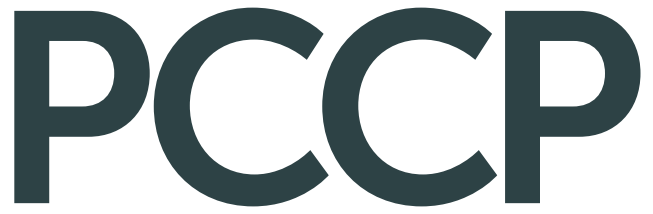

Physical Chemistry Chemical Physics www.rsc.org/pccp
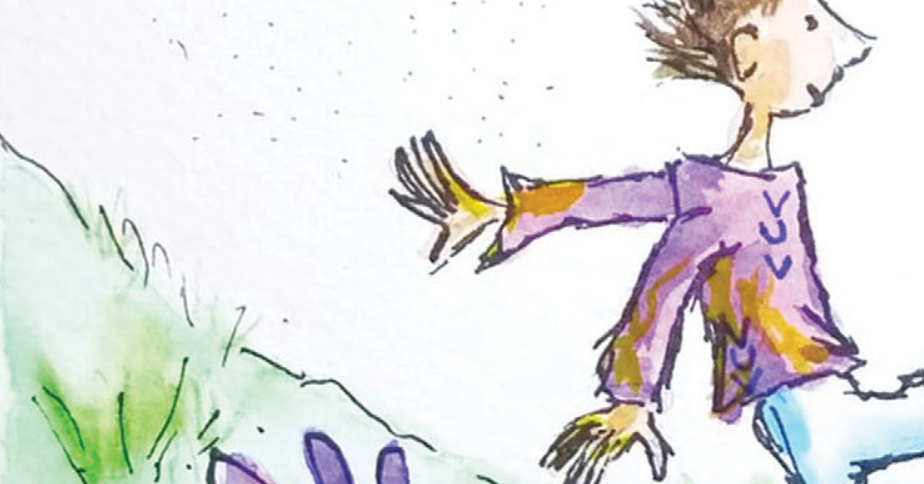

,

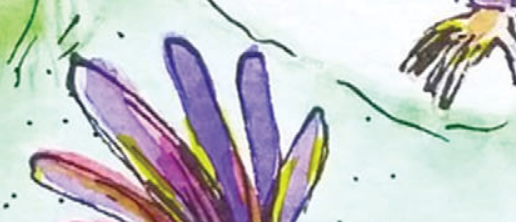

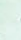
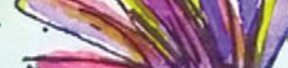

$\therefore \cdots(0)$

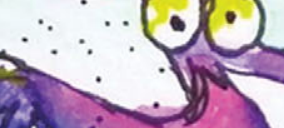

$\therefore \div>$

$\because$

N1

ISSN 1463-9076

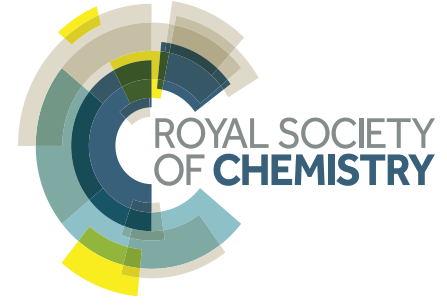




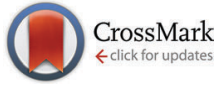

Cite this: Phys. Chem. Chem. Phys., 2015, 17, 28505

Received 21st May 2015,

Accepted 4th August 2015

DOI: $10.1039 / c 5$ cp02944a

www.rsc.org/pccp

\section{Controlling tunnelling in methane loss from acetone ions by deuteration $\uparrow$}

\author{
Andras Bodi, ${ }^{a}$ Tomas Baer, ${ }^{b}$ Nancy K. Wells, ${ }^{c}$ Daniel Fakhoury, ${ }^{c}$ David Klecyngier ${ }^{c}$ \\ and James P. Kercher ${ }^{C}$
}

Energetic acetone cations decay by methane or methyl radical loss. Although the methane-loss barrier to form the ketene cation is higher and the activation entropy is lower, it has a significant branching ratio at low energies thanks to quantum tunnelling. $\mathrm{H}$-atom tunnelling can be selectively quenched and the methaneloss channel suppressed quantitatively by deuteration.

Tunnelling is a well-known phenomenon in physical processes, especially in ones involving electron transfer steps. Frequently, electronic processes occur exclusively as a result of tunnelling, e.g. in scanning tunnelling microscopy. Tunnelling in chemical reactions is generally limited to processes involving the motion of the lightest of atoms, hydrogen. Even in such reactions, tunnelling dominates only in a narrow energy or temperature range, and quickly becomes negligible at energies above the barrier. Evidence for tunnelling can be established experimentally by comparing the reaction dynamics of the molecule with its deuterated analogue. The ratio of the rate constants or product yields is referred to as kinetic isotope effect (KIE). Zero-point energy shifts and tunnelling are the two principal contributors to the deuterium KIE. Deuteration leads to a decrease in the vibrational frequencies, which generally results in an increased activation energy, and deuterium is much less likely than hydrogen to tunnel through barriers, thereby further decreasing the reaction rate. Typical values of the KIE in thermal systems can range between 1 and 20. Indeed such effects are sufficiently large to permit their use in organic synthesis to block unwanted pathways by strategic deuteration. ${ }^{1-4}$ However, disentangling the contribution of the change in activation energy, which is present in all reactions, from the tunnelling contribution, which is only

\footnotetext{
${ }^{a}$ Molecular Dynamics Group, Paul Scherrer Institute, Villigen 5232, Switzerland. E-mail: andras.boedi@psi.ch

${ }^{b}$ Department of Chemistry, University of North Carolina, Chapel Hill, NC 27517, USA

${ }^{c}$ Department of Chemistry, Hiram College, Hiram, OH 44234, USA

$\dagger$ Electronic supplementary information (ESI) available: The vibrational frequencies, and a light acetone breakdown diagram computed without tunnelling contributions. See DOI: 10.1039/c5cp02944a
}

present for reactions with narrow potential barriers, is often difficult. At least in one low-temperature synthesis involving an indole ring lithiation, the value of $k_{\mathrm{H}} / k_{\mathrm{D}}=35$ was of such magnitude that the authors attributed the suppression of the unwanted pathway in the deuterated case to an inability of the deuterated sample to tunnel through a barrier. ${ }^{2}$

Possible applications of tunnelling control go beyond increasing the yield in syntheses. Isotope fractionation in the environment is governed by isotope effects, ${ }^{5}$ and quantum tunnelling often contributes substantially to enzymatic function. ${ }^{6}$ There have been a number of reaction mechanisms, in which tunnelling could play a major but yet unspecified role close to the barrier, such as in the so-called radical roaming mechanism ${ }^{7}$ or in the recently proposed abstraction-induced inversion $\mathrm{S}_{\mathrm{N}} 2$ mechanism. ${ }^{8}$

While tunnelling in thermal systems is often hidden by the broad energy distributions, it can play a dominant role in energy selected systems, in a narrow energy band below the reaction barrier, in which case the reaction proceeds entirely by tunnelling through the barrier. Examples include the low temperature isomerization of matrix isolated methylhydroxycarbene to acetaldehyde, ${ }^{9}$ as well as of tert-butylhydroxycarbene to pivaldehyde. ${ }^{10} \mathrm{H}$-atom tunnelling through barriers can also be rate determining in simple dissociations without a rearrangement step, as was demonstrated by deuteration in H/D-loss from energy selected formic acid ${ }^{11}$ and ethanol ${ }^{12}$ cations.

The role of tunnelling in the dissociation of acetone ions has been debated for many years. At an internal energy of $80-100 \mathrm{~kJ} \mathrm{~mol}^{-1}$, acetone ions dissociate by two paths, either by the loss of a $\mathrm{CH}_{3}$ radical by simple bond rupture or by the loss of $\mathrm{CH}_{4}$, which clearly involves a rearrangement, as shown in Fig. 1. The two ion products formed are the acetyl ion $\left(\mathrm{CH}_{3} \mathrm{CO}^{+}\right)$ and the ketene ion $\left(\mathrm{CH}_{2} \mathrm{CO}^{+}\right)$. It is possible to study slowly dissociating ions in mass spectrometers selectively, and it has been known for a long time that $\mathrm{CH}_{4}$ loss proceeds by the dissociation of a metastable acetone ion. In a study of mixed isotopes, Lifshitz and Tzidony reported a $\mathrm{CD}_{3} \mathrm{H}$ yield 70 times higher than that of $\mathrm{CH}_{3} \mathrm{D}$ in the metastable methane loss from 


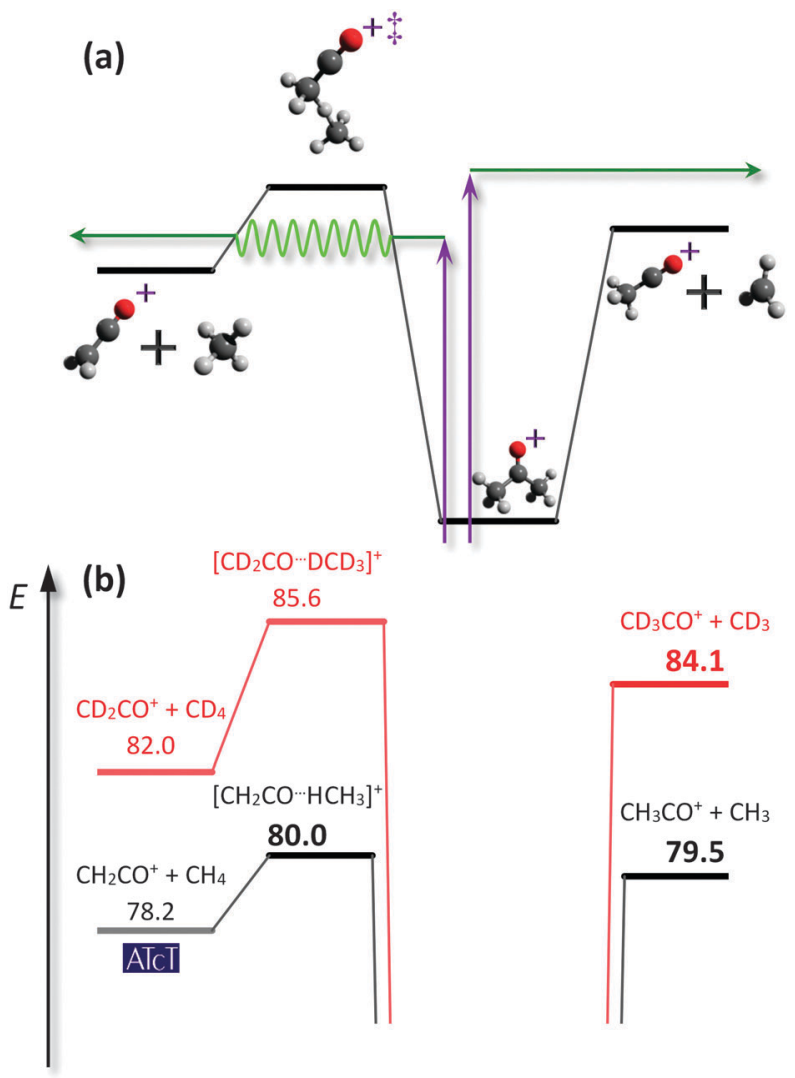

Fig. 1 (a) Schematic and (b) to scale potential energy curves for methane (left) and methyl (right) loss from the acetone cation. Reaction energetics relative to the acetone cation are given in $\mathrm{kJ} \mathrm{mol}^{-1}$ and set in bold for processes measured herein.

$\mathrm{CH}_{3} \mathrm{COCD}_{3}{ }^{+13}$ i.e. a $\mathrm{KIE}$ of 70 , strongly suggesting that tunnelling effects were at play. Indeed, on the basis of theoretical calculations, Heinrich et al. attributed the large KIE to tunnelling. ${ }^{14}$ However, in a subsequent study, Osterheld and Brauman reported a much lower KIE by IR multiphoton dissociation (IRMPD) and concluded that tunnelling was not needed to account for methane abstraction dynamics, ${ }^{15}$ a conclusion later corroborated by Anand and Schlegel in an $a b$ initio trajectory study. ${ }^{16}$

Methane loss can only occur by tunnelling below the energy of its transition state, and will contribute to the reaction dynamics if this energy level lies close by the methyl-loss product energies. However, without internal energy selection, achieved by matrix cooling in neutrals and threshold photoionization by tuneable monochromatic radiation in ions, mechanistic insights can become blurred. Tunnelling rates can be slow with reactant lifetimes in the range of microseconds to hours. Products may thus remain undetected if the detection scheme is too fast. The two most recent photoionization studies on acetone with both internal energy selection and dissociation rate measurements were inconclusive regarding tunnelling, as only light acetone was studied. ${ }^{17,18}$ The branching ratios reported in the IRMPD study ${ }^{15}$ are vastly different from our observations (vide infra), which suggests that a different, potentially non-statistical or isotope sensitive sequential photodissociation reaction route was sampled by Osterheld and Brauman. The computational conclusion of
Anand and Schlegel, ${ }^{16}$ that the methane loss transition sate lies below the threshold to methyl-loss, has been both accepted ${ }^{17}$ and called into question ${ }^{18}$ in later photoionization studies.

In imaging photoelectron photoion coincidence spectroscopy (iPEPICO), the sample is photoionised by monochromatic vacuum ultraviolet radiation, and the photoelectrons and photoions are detected in delayed coincidence. Threshold electrons are selected by velocity map imaging, so that all the excess photon energy above the ionization energy (IE) is deposited as internal energy in the parent ion, ${ }^{19}$ which can then be scanned by tuning the photon energy. The photoions are mass analysed by their time-of-flight (TOF). The use of a long $(5 \mathrm{~cm})$ and soft $\left(120 \mathrm{~V} \mathrm{~cm}^{-1}\right) 1 \mathrm{st}$ acceleration region ensures that dissociation rate constants in the $10^{3}<k / \mathrm{s}^{-1}<10^{7}$ range yield asymmetric daughter ion peaks, from which the rates are directly determined. The iPEPICO experiment $^{20}$ at the VUV beamline ${ }^{21}$ of the Swiss Light Source (SLS) offers an overall energy resolution of $3 \mathrm{meV}\left(0.3 \mathrm{~kJ} \mathrm{~mol}^{-1}\right)$, which can be used to derive comparably accurate thermochemistry as was shown in the case of water and its dimer. ${ }^{22}$ The iPEPICO experiment was also used several times to study primary and secondary kinetic isotope effects and zero point energy shifts. ${ }^{12,23,24}$ It presents an ideal approach for measuring the branching ratios and dissociation rates in methyl and methane loss from the light and deuterated acetone cation to offer incontrovertible proof as to the role of quantum tunnelling.

Acetone-h6 and -d6 (99.9 atom\% D) were obtained from Sigma-Aldrich and introduced in the iPEPICO experiment at room temperature. Fig. 2 shows characteristic TOF distributions at two photon energies for each sample. The fractional abundance of parent and daughter ions as a function of the photon energy is plotted in the breakdown diagram in Fig. 3.

It is important to recall that the sample is at room temperature, and its thermal energy distribution is retained in threshold photoionization. ${ }^{25}$ Because this energy is also available for dissociation, the parent ion signal slowly decreases with increasing photon

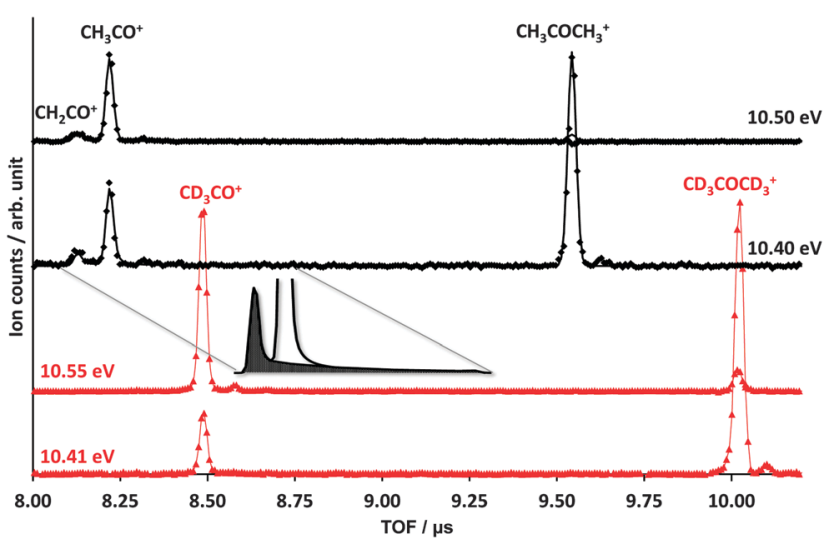

Fig. 2 Representative time-of-flight distributions for acetone-h6 (above) and - $d 6$ (below). Points correspond to measured ion counts, the continuous thick lines to the statistical fit in acetone-h6. The inset shows the asymmetric ketene ion peak in the acetone-h6 model, corresponding to an effective methane loss rate of ca. $10^{7} \mathrm{~s}^{-1}$ (see also Fig. 4). The acetone-d6 TOF data were not fitted, because the dissociation is fast, and the TOF distributions do not contain rate information. 


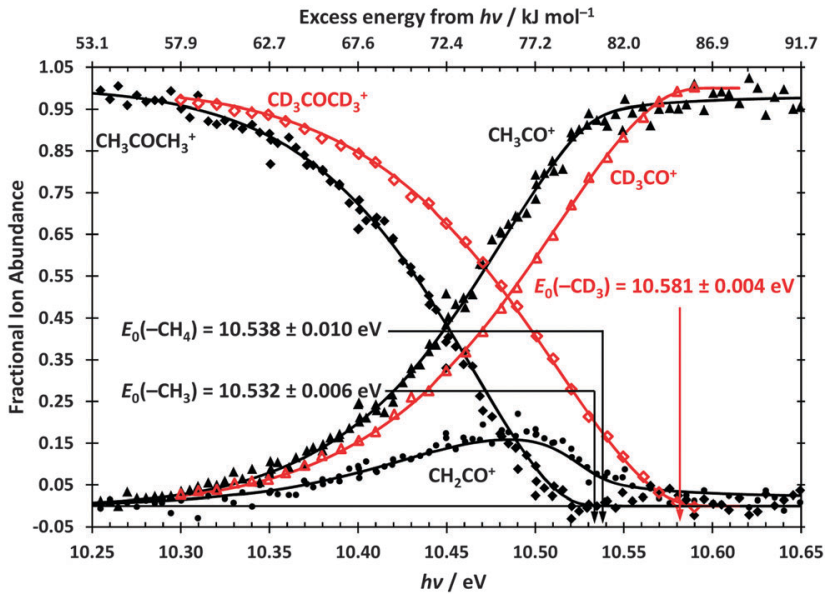

Fig. 3 Breakdown diagram for light (solid symbols) and perdeuterated (open symbols) acetone. The top $x$-axis shows the photon energy in excess of the acetone-h6 ionization energy in $\mathrm{kJ} \mathrm{mol}^{-1}$. Symbols correspond to experimental data and continuous lines show the statistical model fit, which yielded the $0 \mathrm{~K}$ appearance energies. The fitted methane loss appearance energy, $10.538 \mathrm{eV}$, is significantly above the thermochemical onset, $10.519 \mathrm{eV}$ (see below), confirming the existence of a saddle point along the reaction coordinate.

energy and goes to zero only at the $0 \mathrm{~K}$ onset in prompt dissociations. In the mass spectra (Fig. 2), the $\mathrm{CH}_{3} \mathrm{CO}^{+}$peak, which corresponds to methyl loss, is narrow and symmetric, while the $\mathrm{CH}_{2} \mathrm{CO}^{+}$peak, which corresponds to methane-loss, is asymmetrically broadened towards longer TOF. This means that the loss of $\mathrm{CH}_{3}$ is prompt, $k>10^{7} \mathrm{~s}^{-1}$, whereas $\mathrm{CH}_{4}$ loss is a slow dissociation that takes place as the ions are accelerated over the $5 \mathrm{~cm}$ long first acceleration region. In deuterated acetone, the crossover energy, at which half of the parent ion dissociates, is shifted by $50 \mathrm{meV}\left(\sim 5 \mathrm{~kJ} \mathrm{~mol}^{-1}\right)$ to higher photon energy when compared with the light sample, and the $\mathrm{CD}_{4}$-loss channel is suppressed below the detection limit. Based on the signal-to-noise ratio of the TOF distributions, this means that the $\mathrm{CD}_{4}$-loss channel is probably below $1 \%$ and certainly below $2 \%$ in the breakdown diagram.

The $\mathrm{CH}_{3} \mathrm{CO}^{+}: \mathrm{CH}_{2} \mathrm{CO}^{+}$ratio in the breakdown diagram in Fig. 3 corresponds to the branching ratio averaged over the internal energy distribution of the parent ion. Thus, detailed information about the mechanism can only be obtained by modelling of the data that takes into account assumed rate curves for both channels as well as their energetic onsets. The PEPICO modelling program of Sztáray et al., ${ }^{26}$ which has been used in a wide range of studies including ones that involve tunneling $^{11,12}$ as well as competitive reactions, ${ }^{27}$ is ideally suited for analysing these data. However, the large number of model parameters, namely two dissociation energies, the curvature of the methane-loss transition state, the methane-loss thermochemical onset, and the activation entropies, makes it impossible to arrive at firm conclusions. Indeed, two previous TPEPICO studies were able to fit acetone-h6 data, quite similar to those in Fig. 3, assuming different models and reporting different $\mathrm{CH}_{3}$-loss onset energies. ${ }^{17,18}$ What allows us to improve on these prior studies is the additional data set for acetone-d6 as well as the
Table 1 Enthalpies of formation from ATcT, version 1.112

\begin{tabular}{lccl}
\hline & $\Delta_{\mathrm{f}} H_{\mathrm{OK}}^{\theta}$ & $\Delta_{\mathrm{f}} H_{298 \mathrm{~K}}^{\theta} /\left(\mathrm{kJ} \mathrm{mol}^{-1}\right)$ & \\
\hline $\mathrm{CH}_{3} \mathrm{COCH}_{3}(\mathrm{~g})$ & -199.38 & -216.07 & \pm 0.37 \\
$\mathrm{CH}_{3} \mathrm{COCH}_{3}^{+}$ & $737.3^{a}$ & $723.0^{b}$ & \pm 0.4 \\
$\mathrm{CH}_{3} \mathrm{CO}^{+}$ & $666.77^{c}$ & 659.60 & \pm 0.74 \\
$\mathrm{CH}_{2} \mathrm{CO}^{+}$ & 882.11 & 879.10 & \pm 0.15 \\
$\mathrm{CH}_{4}$ & -66.564 & -74.534 & \pm 0.057 \\
$\mathrm{CH}_{3}$ & 149.88 & 146.49 & \pm 0.08
\end{tabular}

${ }^{a}$ Using IE $=9.7081 \pm 0.001 \mathrm{eV} .{ }^{28}{ }^{b}$ Using the W1U calculated thermal enthalpy of $17.4 \mathrm{~kJ} \mathrm{~mol}^{-1}$ and the ion convention. ${ }^{c}$ The most current value in ATcT ver. 1.122 is $667.2 \pm 0.6 \mathrm{~kJ} \mathrm{~mol}^{-1} .{ }^{29}$ The derived methylloss dissociative photoionization thresholds in acetone are $10.530 \pm$ 0.009 and $10.534 \pm 0.007 \mathrm{eV}$ in ATcT ver. 1.112 and 1.122, respectively.

greatly increased accuracy of the thermochemistry associated with the two reaction channels.

In recent years, accurate thermochemical information has become available in part because of high resolution laser studies, ${ }^{28,30}$ as well as advances in theoretical calculations. ${ }^{31,32}$ The heats of formation of acetone, methyl radical, methane, and the ketene and acetyl cations are now all well constrained in the Active Thermochemical Tables (ATcT, Table 1). ${ }^{33,34}$ In particular, the thermochemical dissociation limit to produce the ketene ion and methane is known to be $10.519 \pm 0.004 \mathrm{eV}$, a value that we accept.

The best defined experimental quantity is the methyl-loss onset from acetone-d6 because it is a fast and only dissociation channel. Our approach relies on the computed zero-point energy shift to determine the methyl-loss onset in acetone-h6, a value that can be confirmed by the ATcT values in Table 1 . The modelling of the acetone-h6 data can thus be carried out varying only the isomerization barrier height.

Calculated vibrational frequencies and rotational constants obtained by Gaussian $09^{35}$ at the B3LYP/6-311++G(d,p) level of theory are given in the $\mathrm{ESI}^{\dagger}+$ and used to calculate the thermal energy distribution of the sample and the $a b$ initio RRKM theory rate curves. ${ }^{26}$ Constrained $\mathrm{C}-\mathrm{C}$ bond length scans confirmed that methyl-loss can take place without a saddle point, and the harmonic vibrational frequencies obtained at an optimized geometry with the $\mathrm{C}-\mathrm{C}$ bond length fixed arbitrarily at $3.25 \AA$ were used as input in the RRKM model. Tunnelling through the $\mathrm{H}$ atom transfer barrier was modelled by an Eckart potential incorporated into RRKM theory. ${ }^{36}$ The imaginary frequency at the saddle point along the methane-loss reaction (Fig. 1) has been determined at the optimized geometry with B3LYP/6-311++G(d,p) as well as MP2/aug-cc-pVTZ theories (627i and $600 \mathrm{i} \mathrm{cm}^{-1}$ in acetone-h6, 494i and $461 \mathrm{i} \mathrm{cm} \mathrm{cm}^{-1}$ in acetone-d6, respectively) and the average values were used in the modelling. In the acetone-d6 model, only the methyl-loss $0 \mathrm{~K}$ appearance energy was varied to reproduce the measured breakdown diagram, which yielded $E_{0}=10.581 \pm 0.004 \mathrm{eV}$. By scaling the transitional mode frequencies, we could determine a lower limit to the activation entropy, $\Delta^{\ddagger} S_{600 \mathrm{~K}}>75 \mathrm{~J} \mathrm{~mol}^{-1} \mathrm{~K}^{-1}$, at which the acetyl-d3 peak is still symmetric and narrow at all energies.

The zero-point energy difference between the $\mathrm{CD}_{3}$ - and $\mathrm{CH}_{3}$-loss thresholds was calculated using harmonic frequencies with the B3LYP and M06-2X DFT functionals and the 6-311++G(d,p) basis 
set (51 and $52 \mathrm{meV}$, respectively), and at the MP2/aug-cc-pVTZ and CCSD/cc-pVTZ levels (47 and $48 \mathrm{meV}$, respectively), yielding an average $a b$ initio result of $49 \pm 4 \mathrm{meV}$. Subtracting this value from the $\mathrm{CD}_{3}$-loss threshold implies a $\mathrm{CH}_{3}$-loss onset of $10.532 \pm$ $0.006 \mathrm{eV}$ in acetone-h6. This derived onset agrees within experimental error with the most recent Active Thermochemical Tables predicted onset of $10.534 \pm 0.007 \mathrm{eV}$ (see Table 1), in which the acetyl ion heat of formation is mostly defined by an $\mathrm{OH}$-loss dissociative photoionization measurement of acetic acid by Shuman et al. ${ }^{37}$ The thermochemical onsets for both $\mathrm{CH}_{4^{-}}$and $\mathrm{CH}_{3}$-loss reactions in acetone-h6 are therefore precisely known at $10.519 \pm 0.004 \mathrm{eV}$ (Table 1) and $10.532 \pm 0.006 \mathrm{eV}$, respectively. Furthermore, by applying the computed isotope effects and calculating $\mathrm{CD}_{4}$-loss rates in acetone-d6, we can determine a minimum reverse barrier of $40 \mathrm{meV}$ or $3.6 \mathrm{~kJ} \mathrm{~mol}^{-1}$, which is necessary to suppress the methane-loss channel to below $2 \%$ at all energies in the breakdown diagram, as observed experimentally. This translates into a $1.9 \mathrm{~kJ} \mathrm{~mol}^{-1}$ lower limit to the reverse barrier in light acetone, which agrees within the error limits with the $\mathrm{W} 1$-computed ${ }^{32}$ reverse barrier of $1.8 \mathrm{~kJ} \mathrm{~mol}^{-1}$. The optimized value in the light acetone fit using the computed imaginary frequency of $614 \mathrm{i} \mathrm{cm}^{-1}$ is $1.8 \mathrm{~kJ} \mathrm{~mol}^{-1}$ yielding the model shown in Fig. 3. An assumed $\pm 100 \mathrm{~cm}^{-1}$ error bar on the imaginary frequency results in a $\pm 0.25 \mathrm{~kJ} \mathrm{~mol}^{-1}$ uncertainty in the reverse barrier. Thus, we find that the $\mathrm{CH}_{4}$-loss barrier lies at $80.0 \mathrm{~kJ} \mathrm{~mol}^{-1}$, which is barely above the $\mathrm{CH}_{3}$ loss onset. The resulting methyl- and methane-loss rate curves and branching ratios in acetone-h6 and -d6 are shown in Fig. 4. By calculating the breakdown diagram of light acetone without tunnelling (see ESI $\dagger$ ), we can determine that $80 \%$ of the $\mathrm{CH}_{4}$ abstraction signal is indeed due to $\mathrm{H}$-atom tunnelling at a photon energy of $10.49 \mathrm{eV}$.

Two previously mentioned PEPICO studies have addressed the acetone ion dissociation and obtained different experimental

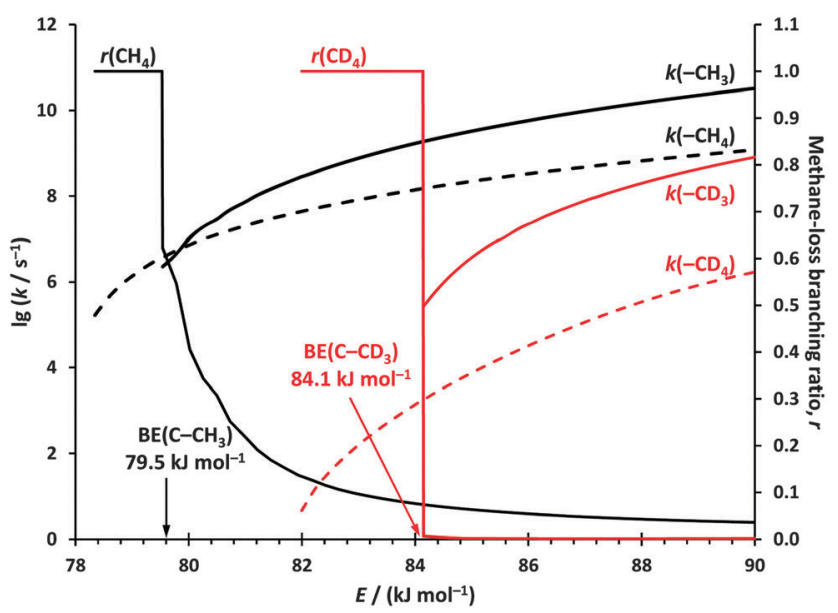

Fig. 4 Rate curves for methyl and methane loss from acetone-h6 and - $\mathrm{d} 6$ ions, plotted together with methane-loss branching ratios as a function of the internal energy of the parent ion. Even though the tunnelling energy range is slightly larger in perdeuterated acetone, the tunnelling rates are so slow that alternative relaxation processes, e.g. IR emission, are likely to outcompete the dissociation, and only direct $\mathrm{C}-\mathrm{C}$ bond breaking is possible leading to the acetyl cation. onset energies. Fogleman et al. ${ }^{18}$ did not model the $\mathrm{CH}_{4}$-loss rate curve, but noting that it was metastable and unable to compete with methyl loss, added its contribution to the parent ion and arrived at a $0 \mathrm{~K} \mathrm{CH}_{3}$-loss onset of $10.563 \pm 0.010 \mathrm{eV}$. Later, Rennie et al. ${ }^{17}$ modelled the $\mathrm{CH}_{4}$ loss channel but ignored tunnelling, and reported $\mathrm{CH}_{3}$ and $\mathrm{CH}_{4}$ loss onsets of 10.516 and $10.485 \pm 0.020 \mathrm{eV}$, respectively. Our values shown in Fig. 3, which include tunnelling in the $\mathrm{CH}_{4}$ loss channel, differ significantly from the two previous measurements. It is interesting that the three breakdown diagrams are nearly identical and that the different onset energies arise only because of the different assumed rate mechanisms. The derived thermochemistry, however, is only consistent with the Active Thermochemical Tables if tunnelling is explicitly taken into account. Furthermore, zero point energy isotope effects are insufficient to explain the suppression of the methane-loss channel in acetone-d6. These two observations provide strong evidence of tunnelling control in $\mathrm{CH}_{4}$-loss in acetone-h6 cations below an internal energy of $100 \mathrm{~kJ} \mathrm{~mol}^{-1}$.

\section{Conclusions}

Light and perdeuterated acetone were ionized and the dissociation of the internal energy selected parent ions studied by imaging photoelectron photoion coincidence. Based on the mass spectra, methyl loss yielding the acetyl cation is a fast process in both samples, whereas methane loss leading to the ketene cation is initially a slow process in acetone-h6, quickly outcompeted by methyl loss, and absent in acetone-d6. While modelling the light acetone data alone does not yield an unequivocal result regarding the tunnelling control of methane loss, we can establish a lower limit to the reverse barrier because of the absence of the analogous fragment ion in perdeuterated acetone. Furthermore, the derived thermochemistry is only consistent with the literature if tunnelling is included in the model. The experimental evidence in conjunction with $a b$ initio isotope effect calculations thus shows that the activation energy of methane abstraction lies above the methyl loss energy, and that as much as $80 \%$ of the methane abstraction is a result of quantum tunnelling, which can be completely suppressed by deuteration. The derived methyl-loss dissociative photoionization onset in light acetone is $10.532 \pm 0.006 \mathrm{eV}$, a result that will further reduce the uncertainty of the acetyl cation enthalpy of formation in ATcT.

\section{Acknowledgements}

The photoionization experiments were carried out at the VUV beamline of the Swiss Light Source at the Paul Scherrer Institute. Financial support by the Swiss Department of Energy (BFE \#100708) and the American Chemical Society Petroleum Research Fund (PRF \#51896-UNI4) is also gratefully acknowledged. We are thankful to Dr Jonelle Harvey for the table-of-contents drawing.

\section{Notes and references}

1 D. L. J. Clive, M. Cantin, A. Khodabocus, X. Kong and Y. Tao, Tetrahedron, 1993, 49, 7917-7930.

2 E. Vedejs and J. Little, J. Am. Chem. Soc., 2002, 124, 748-749. 
3 M. Miyashita, M. Sasaki, I. Hattori, M. Sakai and K. Tanino, Science, 2004, 305, 495-499.

4 K. W. Quasdorf, A. D. Huters, M. W. Lodewyk, D. J. Tantillo and N. K. Garg, J. Am. Chem. Soc., 2012, 134, 1396-1399.

5 T. C. Schmidt, L. Zwank, M. Elsner, M. Berg, R. U. Meckenstock and S. B. Haderlein, Anal. Bioanal. Chem., 2004, 378, 283-300.

6 M. Garcia-Viloca, J. Gao, M. Karplus and D. G. Truhlar, Science, 2004, 303, 186-195.

7 J. M. Bowman, Mol. Phys., 2014, 112, 2516-2528.

8 I. Szabó and G. Czakó, Nat. Commun., 2015, 6, 5972.

9 P. R. Schreiner, H. P. Reisenauer, D. Ley, D. Gerbig, C.-H. Wu and W. D. Allen, Science, 2011, 332, 1300-1303.

10 D. Ley, D. Gerbig and P. R. Schreiner, Chem. Sci., 2013, 4, 677.

11 N. S. Shuman, M. Johnson, W. R. Stevens, M. E. Harding, J. F. Stanton and T. Baer, J. Phys. Chem. A, 2010, 114, 10016-10023.

12 A. Bodi, M. D. Brannock, B. Sztáray and T. Baer, Phys. Chem. Chem. Phys., 2012, 14, 16047-16054.

13 C. Lifshitz and E. Tzidony, Int. J. Mass Spectrom. Ion Processes, 1981, 39, 181-195.

14 N. Heinrich, F. Louage, C. Lifshitz and H. Schwarz, J. Am. Chem. Soc., 1988, 110, 8183-8192.

15 T. H. Osterheld and J. I. Brauman, J. Am. Chem. Soc., 1992, 114, 7158-7164.

16 S. Anand and H. B. Schlegel, Phys. Chem. Chem. Phys., 2004, 6, 5166.

17 E. E. Rennie, A.-M. Boulanger, P. M. Mayer, D. M. P. Holland, D. A. Shaw, L. Cooper and L. G. Shpinkova, J. Phys. Chem. A, 2006, 110, 8663-8675.

18 E. A. Fogleman, H. Koizumi, J. P. Kercher, B. Sztáray and T. Baer, J. Phys. Chem. A, 2004, 108, 5288-5294.

19 T. Baer, B. Sztáray, J. P. Kercher, A. F. Lago, A. Bodi, C. Skull and D. Palathinkal, Phys. Chem. Chem. Phys., 2005, 7, 1507-1513.

20 A. Bodi, M. Johnson, T. Gerber, Z. Gengeliczki, B. Sztáray and T. Baer, Rev. Sci. Instrum., 2009, 80, 34101.

21 M. Johnson, A. Bodi, L. Schulz and T. Gerber, Nucl. Instrum. Methods Phys. Res., Sect. A, 2009, 610, 597-603.

22 A. Bodi, J. Csontos, M. Kállay, S. Borkar and B. Sztáray, Chem. Sci., 2014, 5, 3057-3063.

23 S. Borkar, B. Sztáray and A. Bodi, Phys. Chem. Chem. Phys., 2011, 13, 13009-13020.

24 B. L. Yoder, K. B. Bravaya, A. Bodi, A. H. C. West, B. Sztáray and R. Signorell, J. Chem. Phys., 2015, 142, 114303.

25 S. Borkar and B. Sztáray, J. Phys. Chem. A, 2010, 114, 6117-6123.
26 B. Sztáray, A. Bodi and T. Baer, J. Mass Spectrom., 2010, 45, 1233-1245.

27 A. Bodi, Á. Kvaran and B. Sztáray, J. Phys. Chem. A, 2011, 115, 13443-13451.

28 R. T. Wiedmann, L. Goodman and M. G. White, Chem. Phys. Lett., 1998, 293, 391-396.

29 B. Ruscic, private communication of unpublished ATcT results, 2015.

30 A. M. Schulenburg, C. Alcaraz, G. Grassi and F. Merkt, J. Chem. Phys., 2006, 125, 104310.

31 A. Tajti, P. G. Szalay, A. G. Csaszar, M. Kallay, J. Gauss, E. F. Valeev, B. A. Flowers, J. Vazquez and J. F. Stanton, J. Chem. Phys., 2004, 121, 11599-11613.

32 E. C. Barnes, G. A. Petersson, J. A. Montgomery, M. J. Frisch and J. M. L. Martin, J. Chem. Theory Comput., 2009, 5, 2687-2693.

33 B. Ruscic, R. E. Pinzon, M. L. Morton, G. Laszevski, S. J. Bittner, S. G. Nijsure, K. A. Amin, M. Minkoff and A. F. Wagner, J. Phys. Chem. A, 2004, 108, 9979-9997.

34 B. Ruscic, R. E. Pinzon, G. von Laszewski, D. Kodeboyina, A. Burcat, D. Leahy, D. Montoy and A. F. Wagner, J. Phys.: Conf. Ser., 2005, 16, 561-570.

35 M. J. Frisch, G. W. Trucks, H. B. Schlegel, G. E. Scuseria, M. A. Robb, J. R. Cheeseman, G. Scalmani, V. Barone, B. Mennucci, G. A. Petersson, S. Nakatsuji, M. Caricato, H. P. Hratchian, A. F. Izmaylov, J. Bloino, G. Zheng, J. L. Sonnenberg, M. Hada, M. Ehara, K. Toyota, R. Fukuda, J. Hasegawa, M. Ishida, T. Nakajima, Y. Honda, O. Kitao, H. Nakai, T. Vreven, J. A. J. A. Montgomery, J. E. Peralta, F. Ogliaro, M. Bearpark, J. J. Heyd, E. Brothers, K. N. Kudin, V. N. Staroverov, R. Kobayashi, J. Normand, K. Raghavachari, A. Rendell, J. C. Burant, S. S. Iyengar, J. Tomasi, M. Cossi, N. Rega, N. J. Millam, M. Klene, J. E. Knox, J. B. Cross, V. Bakken, C. Adamo, J. Jaramillo, R. Gomperts, R. E. Stratmann, O. Yazyev, A. J. Austin, R. Cammi, C. Pomelli, J. W. Ochterski, R. L. Martin, K. Morokuma, V. G. Zakrzewski, G. A. Voth, P. Salvador, J. J. Dannenberg, S. Dapprich, A. D. Daniels, O. Farkas, J. B. Foresman, J. V Ortiz, J. Cioslowski, D. J. Fox, H. Nakatsuji, X. Li and J. N. Millam, Gaussian 09, Revision C.1, Gaussian, Inc., Wallingford, CT, 2009.

36 T. Baer and W. L. Hase, Unimolecular Reaction Dynamics: Theory and Experiments, Oxford University Press, New York, 1996.

37 N. S. Shuman, W. R. Stevens and T. Baer, Int. J. Mass Spectrom., 2010, 294, 88-92. 